\title{
Response of Varieties to Air-Layering in Olive Cultivars
}

\author{
Waseem Zaman ${ }^{1 *}$, Faheem Ul Haq ${ }^{1}$, Muhammad Ilyas ${ }^{1}$, Binyamin Khan ${ }^{1}$, Muhammad Mehran Anjum², Nawab \\ $\mathrm{Ali}^{2}$ and Shamsher $\mathrm{Ali}^{3}$
}

${ }^{1}$ Department of Horticulture, University of Agriculture, Pakistan,

${ }^{2}$ Department of Agronomy, the University of Agriculture, Pakistan

${ }^{3}$ Department of Soil and Environmental Science, University of Agriculture, Pakistan

Submission: June 10, 2017; Published: July 05, 2017

*Corresponding author: Waseem Zaman, Department of Horticulture, the University of Agriculture Peshawar Pakistan, Amir Muhammad Khan

Abstract

An experiment to investigate "The response of varieties to air-layering in Olive cultivars" was conducted at Olive Research Farm Sangbatti, Agricultural Research Institute (ARI) Tarnab, Peshawar, Pakistan during july 2016. Air layering was done in June Olive cultivars i-e Local variety, Leccino variety, Pendolino variety, Coratino variety and chetoui variety were compared. The experiment was laid out on a single factor RCB-Design (randomized complete block design) having three replications. Maximum root diameter (1.42 mm), number of roots plant ${ }^{-1}$ (6), Minimum days to callus formation (20days) and rooting (55 days) were recorded for Leccino. And maximum root length $(5.56 \mathrm{~cm})$ and weight $(0.67 \mathrm{gm})$ were recorded for local variety. While minimum root length $(1.5 \mathrm{cmcm})$, root diameter $(1.13 \mathrm{~mm})$, root weight $(0.17 \mathrm{gm})$ and number of roots plant ${ }^{-1}$ (1.66), Maximum days to callus formation (27days) and rooting (68days) were recorded for coratina. On the basis of these results it was concluded that Leccino variety performed best in response to days to callus formation, rooting, diameter and number of roots through air layering in different Olive cultivars.

Keywords: Olive; Air-Layering; Cultivars; Mardan

\section{Introduction}

Olive is mentioned in these Verses of the Holy Quran; "ALLAH is the light of the heavens and the earth. The parable of His light is as (if there were) a niche and within it a lamp: the lamp is in a glass, the glass as it were a brilliant star, illuminated from a blessed tree, an Olive, neither of the east (i.e. neither it gets sun-rays only in the morning) nor of the west (i.e. nor it gets sun-rays only in the afternoon, but it is exposed to the sun all day long), whose oil would almost glow forth (of itself), though no fire touched it. Light upon Light! ALLAH guides to His Light whom He wills. And ALLAH sets forth parables for mankind, and ALLAH is All-Knower of everything." [Al-Quran, An-Noor (The Light), 24:35]. Prophetic medicine also described health benefits of Olive tree and Olive oil. Muhammad (S.A.W.W) is reported to have said: "Take oil of Olive and massage with it, it is a blessed tree [1]. Olive (Olea europaea L.) belongs to family Oleaceae and locally called as Zaitoon is an attractive evergreen tree with greygreen foliage. It is a slow and steady growing tree having a long life of about 900 to 1000 years [2]. It was under cultivation long before the time of earliest recorded history. It was originated in the Eastern Mediterranean area. Then after that the cultivation began in Italy, Spain and North Africa. In Asia, cultivation is confined to Iraq, Iran and China [2].
Olive is successfully grown in a climate having moderate cold winters and prolonged hot summers with low humidity. Temperature below $10 \mathrm{oC}$ is injurious as it may kill the plant. Winter rest is considered essential for fruit bud differentiation. Most cultivars require at least two months of winter chilling for floral bud initiation. It is one of the most drought resistant trees and thrives well where the annual average rainfall is around 900-1000 mm without irrigation. It grows well on many different kinds of soil, ranging from rocky shallow hillsides to deep fertile valley soils, from acid soils to fairly alkaline soils. It can also tolerate considerable salinity too. However it can't withstand poorly drained soils and quickly dies if water stands around its roots for few weeks [3].

The Olive tree is shrubby in appearance, and evergreen. The trunk is 4-5 m high, and branches are erect, internodes are elongate reaching $20-60 \mathrm{~mm}$. The bark is smooth, grey-brown. Leaves are lanceolate aspect, they are 3-4 to 7-8 cm long and 0.4 to $1.2-1.3 \mathrm{~cm}$ wide .they are slightly contracted into an acuminate reddish-brown apex and progressively contracted into medium petiole $0.2-0.7 \mathrm{~cm}$ long. Lateral veins are not visible; the median vein is partly canaliculated on the scattered with tectorous and 
star - like hairs above, whitish and densely covered by flattened tectorouse hairs beneath. Flowers are rather large than 4-6 $\mathrm{mm}$ long with 2 bracteoles-elongate of 1-2 $\mathrm{mm}$,inserted either on the pedicel or beneath the calyx is erect,cylindrical - oval1 $\mathrm{mm}$ long. Fruit are borne in panicales .The fruit is a globose - ovoid drupe ; 5 - $7 \mathrm{~mm}$ in diameter and $9-11 \mathrm{~mm}$ long, green then red-brown when unripe, becoming purplish- black. Drupe pulp is sweet or slightly bitter taste [4].

Olive oil reduces blood pressure, lowers the risk of heart attacks, have laxative, anti-inflammatory, anti-carcinogenic and anti-oxidant benefits. Moreover, Olive products help to satisfy the nutritional needs of the population. The fruit contain around $20 \%$ oil and has very less cholesterol. Olive fruits contain $80 \%$ unsaturated fatty acid compared with $20 \%$ saturated ones. Ripe Olive fruits are pressed for rich oil which is the best oil available in the world for edible purposes. The Olive oil has twice as much energy value than sugar. Olive oil contains high percentage of oleic acid which is very essential for our body. Mature fruit are also eaten after being processed and preserved in vinegar or salt solution The Olive oil is used for cooking, salad dressing, food preparation, massage and for the manufacture of cosmetics, pharmaceuticals, [5].

The Olive tree, a universal symbol of peace has been the object of conflict in the Arab-Israel conflict. The uprooting of ancient olive trees, as a by-product of war, has tremendous effects on Palestinian agriculture, economy and identity. In Palestine, the Olive tree is prized for its historical presence, its beauty, and its symbolic significance and most importantly for its economic importance. Olive trees are a major commercial crop for Palestine and many families depend on it for their livelihood [6]. Asexual or vegetative propagation methods probably the most widely used commercial method of propagation in Olive. Olive is propagated through sexual and asexual means. Propagation of Olive through sexual mean is usually not recommended, because seedlings are not true to type and take a lot of time to bear fruit. Air-layering is the effective method of asexual propagation in Olive. Air-layering is usually done in the months of June, July and August. There are six common types of layering: air, simple, tip, trench, serpentine and mound, of which air and simple layering are the most popular types [7].

Some plants which are difficult to root, air layering has been proven as an effective method in a wide range of species as a means of increasing their kind. Air layering is a method which was originated by the Chinese several centuries ago. Basically it is a method of producing plants from aerial branches which remained attached with parent plant and develops rooting. There are many commercial growing media used to raise seedlings and branches, but many are expensive and locally unavailable. There is a need to establish appropriate and low cost growing media to ensure that the tree seedlings could attain a suitable size for layering within a year. Amending growing media with fertilizer can promote seedling and branching growth, establishment and survival [8]. The moist medium for rooting is usually placed around the wounded area of the branch. It is held in position by placing a wrapping around the periphery of the ball of the medium. After the roots have grown to the outside of the ball of medium, the branch is removed and planted in a pot on its own roots. The growth, establishment and survival of branches and seedlings also depend on the quality of a growing medium.

The study of the effect of growing location, variety, and extraction conditions on Olive oil constituents is strongly encouraged. Moreover, with this product being particularly important in terms of human health effects, papers dealing with the in vivo and in vitro studies of olive oils or Olive oil compounds will be accepted (Table 1). A project for Olive promotion in Sangbhatti Olive farm [9-12], a research section of Agricultural Research Institute Tarnab, Peshawar, situated at Mardan District of Khyber Pakhtunkhwa, is initiated to find the suitable cultivars for the regions of Khyber Pakhtunkhwa. Plenty of work is done there on propagation, of which air-layering is the most successful and frequently used technique. Many cultivars are under trail like Koroneik, Leccino, Arbesona, Frontoea and Coratina etc.

Table 1: Study of the effect of growing location, variety, and extraction conditions on Olive oil constituents.

\begin{tabular}{|c|c|c|}
\hline Coratina & Italy & $\begin{array}{l}\text { One of the most important Italian varieties, } \\
\text { especially favoured in the area of Puglia, the } \\
\text { largest Olive growing area of Italy. }\end{array}$ \\
\hline Leccino & Italy & $\begin{array}{c}\text { And Frantoio cultivars are the principal raw } \\
\text { material for Italian Olive oils from Tuscany. } \\
\text { Leccino has a mild sweet flavour. }\end{array}$ \\
\hline Pendolino & Italy & $\begin{array}{l}\text { Somewhat light bearing, especially when } \\
\text { compared to precocious cultivars such as } \\
\text { Leccino, but relatively constant bearing. }\end{array}$ \\
\hline Chetoui & Tunisia & $\begin{array}{l}\text { Chetoui is the second main Olive variety } \\
\text { cultivated in the north of Tunisia and shows } \\
\text { a high capacity of adaptation to various } \\
\text { pedoclimatic conditions. }\end{array}$ \\
\hline
\end{tabular}

\section{Objectives}

Keeping in view the value of Olive and air layering an experiment was designed with the following objectives;

To find out the best variety for Olive air-layering under the agro-climatic conditions of Mardan.

\section{Materials and Methods}

An experiment was conducted at Olive Research Farm Sangbatti, Agricultural Research Institute (ARI) Tarnab, Peshawar, in order to evaluate the response of varieties to air layering in the agro climatic conditions of mardan during july 2016. Five varieties i.e. local variety, Coratina, Leccino, Pendolino and Chetoui were compared [13].

\section{Experimental Layout}

The experiment was laid out in Randomized Complete Block (RCB) [14,15] design having single factor. In which each 
treatment was repeated three times. Nine air-layers per tree were practiced. In this way a single replication had 45 air-layers (5trees x 9 layers), thus a total of 135 air-layers were made in three replications.

The experiment consisted of a single factor:

Factor: Different varieties;

Variety 1: local variety

Variety 2: Coratina

Variety 3: Leccino

Variety 4: Pendolino

Variety 5: Chetoui

\section{Preparation of Air-Layers}

In order to initiate rooting in Olive cultivars (Local variety, Coratina variety, Leccino variety, and Pendolino and Chetoui varieties) branches a circular strip of bark having $3 \mathrm{~cm}$ size was completely removed just below the buds from one year old shoots. The branches used for air-layering had $1.5 \mathrm{~m}$ length and pencil size thickness. The plants selected for the experiment were seven years old [16-20]. A heavy mass of well-prepared selected media was tightly wrapped around layered branches readily after the removal of bark to reduce moisture loss from the opened portion. The media were covered with polyethylene sheets to make sure that the media remain intact. All the air layered plants were frequently irrigated after the completion of air layering practice. Data were collected after 10-15 days. The branches which showed successful development of roots in media were cut off carefully below the layered portion from parent plants and data were recorded for different parameters [21]. All other cultural practices were kept uniform for all the treatments during this course of experiment.

\section{Results and Discussion}

\section{Days to callus formation}

The data recorded for days to callus formation is given in (Table 2) and analysis of variance is presented in (Table 2a). The analysis of variance showed that data related to days to callus formation were non-significantly different. The mean table showed that minimum days to callus formation were recorded for Leccino (20days), followed by Local variety (23.66 days), while maximum days to callus formation were in Coratina $(27$ days). The difference in days to callus formation for different varieties is related to the climatic condition of Mardan. Its seems that Coratina does not have more favorable climatic condition compared to the Leccino. Leccino is more favorable to the climate of Mardan then that of other varieties that why Leccino variety showed better results for callus formation. It is noticed that early callus formation occurred in Leccino. While late callus formation occurred in Coratino.
Table 2: Effect of air layering with different varieties on days to callus formation in Olive varieties.

\begin{tabular}{|c|c|c|c|c|}
\hline \multirow{2}{*}{ Varieties } & \multicolumn{3}{|c|}{ Replications } & \multirow{2}{*}{ Mean } \\
\cline { 2 - 4 } & R1 & R2 & R3 & \\
\hline Local variety & 25 & 24 & 22 & 23.66 \\
\hline Leccino & 20 & 21 & 19 & 20 \\
\hline Pendolino & 23 & 25 & 25 & 25 \\
\hline Coratina & 27 & 28 & 26 & 27 \\
\hline Chetoui & 30 & 21 & 29 & 26.66 \\
\hline
\end{tabular}

Table 2a: Analysis of variance for days to Callus Formation through air layering with different Olive varieties.

\begin{tabular}{|c|c|c|c|c|c|}
\hline Source & DF & SS & MS & F & P \\
\hline Repli & 2 & 3.733 & 1.8667 & & \\
\hline Varieties & 4 & 95.333 & 23.8333 & 3.39 & 0.0667 \\
\hline Error & 8 & 56.267 & 7.0333 & & \\
\hline Total & 14 & 155.333 & & & \\
\hline Grand mean & 24.333 & $\mathrm{Cv}$ & 10.90 & & \\
\hline
\end{tabular}

\section{Days to rooting}

Table 3: Effect of air layering with different varieties on days to rooting in Olive varieties.

\begin{tabular}{|c|c|c|c|c|}
\hline Varieties & \multicolumn{3}{|c|}{ Replications } & Mean \\
\hline & R1 & R2 & R3 & \\
\hline Local variety & 61 & 58 & 58 & 58.66 \\
\hline Leccino & 54 & 56 & 55 & 55 \\
\hline Pendlino & 63 & 62 & 60 & 61.66 \\
\hline Coratina & 67 & 72 & 72 & 68 \\
\hline Chetoui & 56 & 53 & 53 & 58.66 \\
\hline
\end{tabular}

Table 3a: Analysis of variance for days to rooting through air layering with different Olive varieties.

\begin{tabular}{|c|c|c|c|c|c|}
\hline Source & DF & SS & MS & F & P \\
\hline Repli & 2 & 2.133 & 1.0667 & & \\
\hline Varieties & 4 & 280.400 & 70.1000 & 3.86 & 0.0429 \\
\hline Error & 8 & 145.200 & 18.1500 & & \\
\hline Total & 14 & 427.733 & & & \\
\hline Grand mean & 60.467 & Cv & 7.05 & & \\
\hline
\end{tabular}

LSD value at $5 \%$ of Probability $=8.0214$

The data recorded for days to rooting is given in (Table 3) and analysis of variance is presented in (Table $3 a$ ). The analysis of variance showed that data related to days to rooting were significantly different. The mean table showed that minimum days to rooting were recorded for Leccino (55days), followed by Local variety and Chetoui (58.66 days), while maximum days to rooting were in Coratina (68 days). The difference in days to rooting for different varieties is related to the climatic condition of Mardan. Its seems that Coratina does not have more favorable climatic condition compared to the Leccino. Leccino is more favorable to the climate of Mardan then that of other varieties that's why Leccino variety showed better results for rooting. It is 
noticed that early rooting occurred in Leccino. While late rooting occurred in Coratina variety.

\section{Root diameter ( $\mathrm{mm}$ )}

The data recorded for root diameter is given in (Table 4) and analysis of variance is presented in (Table $4 \mathrm{a}$ ). The analysis of variance showed that data related to root diameter were significantly different. The mean table showed that maximum root diameter were recorded for Leccino $(1.42 \mathrm{~mm})$, followed by Chetoui $(1.32 \mathrm{~mm})$, while minimum root diameter were in Coratina variety $(1.13 \mathrm{~mm})$. The difference in root diameter for different varieties is related to the climatic condition of Mardan. Its seems that Coratina does not have more favorable climatic condition compared to the Leccino. Leccino is more favorable to the climate of Mardan then that of other varieties that why Leccino variety showed better results for root diameter [22]. It is noticed that maximum root diameter occurred in Leccino. While minimum root diameter occurred in Coratina variety.

Table 4: Effect of air layering with different varieties on root diameter $(\mathrm{mm})$ in Olive varieties.

\begin{tabular}{|c|c|c|c|c|}
\hline \multirow{2}{*}{ Varities } & \multicolumn{3}{|c|}{ Replications } & \multirow{2}{*}{ Mean } \\
\cline { 2 - 4 } & R1 & R2 & R3 & \\
\hline Local variety & 1.15 & 1.22 & 1.35 & 1.24 \\
\hline Leccino & 1.32 & 1.45 & 1.49 & 1.42 \\
\hline Pendolino & 1.13 & 1.21 & 1.42 & 1.25 \\
\hline Coratina & 1.1 & 1 & 1.33 & 1.13 \\
\hline Chetoui & 1.29 & 1.33 & 1.36 & 1.32 \\
\hline
\end{tabular}

Table 4a: Analysis of variance for root diameter $(\mathrm{mm})$ through air layering with different Olive varieties.

\begin{tabular}{|c|c|c|c|c|c|}
\hline Source & DF & SS & MS & F & P \\
\hline Repli & 2 & 0.10117 & 0.05059 & & \\
\hline Varieties & 4 & 0.12813 & 0.03203 & 6.43 & 0.0128 \\
\hline Error & 8 & 0.03983 & 0.00498 & & \\
\hline Total & 14 & 0.26913 & & & \\
\hline Grand mean & 1.2767 & $\mathrm{Cv}$ & 5.53 & & \\
\hline
\end{tabular}

LSD value at $5 \%$ of Probability $=0.1328$

\section{Root length (cm)}

Table 5: Effect of air layering with different varieties on root length $(\mathrm{cm})$ in Olive varieties.

\begin{tabular}{|c|c|c|c|c|}
\hline \multirow{2}{*}{ Varieties } & \multicolumn{3}{|c|}{ Replications } & \multirow{2}{*}{ Mean } \\
\cline { 2 - 4 } & $\mathbf{R 1}$ & $\mathbf{R 2}$ & $\mathbf{R 3}$ & \\
\hline $\begin{array}{c}\text { Local } \\
\text { variety }\end{array}$ & 5.2 & 5.8 & 5.7 & 5.56 \\
\hline Leccino & 3.4 & 3.5 & 4.1 & 3.66 \\
\hline Pendolino & 1.5 & 1.9 & 2.7 & 2.03 \\
\hline Coratina & 1 & 2 & 1.5 & 1.5 \\
\hline Chetoui & 4.3 & 4.6 & 4.1 & 4.33 \\
\hline
\end{tabular}

The data recorded for root length is given in (Table 5) and analysis of variance is presented in (Table 5a). The analysis of variance showed that data related to root length were significantly different. The mean table showed that maximum root length was recorded for Local variety $(5.56 \mathrm{~cm})$, followed by Chetoui $(4.33 \mathrm{~cm})$, while minimum root length were in Coratina $(1.5 \mathrm{~cm})$. The difference in root length for different varieties is related to the climatic condition of Mardan. Its seems that Coratina does not have more favorable climatic condition compared to the Local variety [23]. Local variety is more favorable to the climate of Mardan then that of other varieties that's why Local variety showed better results for root length. It is noticed that maximum root length occurred in Local variety. While minimum root length occurred in Coratino variety.

Table 5a: Analysis of variance for root length $(\mathrm{cm})$ through air layering with different Olive varieties.

\begin{tabular}{|c|c|c|c|c|c|}
\hline Source & DF & SS & MS & F & P \\
\hline Repli & 2 & 0.8760 & 0.43800 & & \\
\hline Varieties & 4 & 33.3373 & 8.33433 & 67.30 & 0.0000 \\
\hline Error & 8 & 0.9907 & 0.12383 & & \\
\hline Total & 14 & 35.2040 & & & \\
\hline Grand mean & 3.4200 & $\mathrm{Cv}$ & 10.29 & & \\
\hline
\end{tabular}

LSD value at $5 \%$ of Probability $=0.6626$.

\section{Number of roots per plant ${ }^{1}$}

Table 6: Effect of air layering with different varieties on number of roots plant $^{-1}$ in Olive varieties.

\begin{tabular}{|c|c|c|c|c|}
\hline \multirow{2}{*}{ Varieties } & \multicolumn{3}{|c|}{ Replications } & \multirow{2}{*}{ Mean } \\
\cline { 2 - 4 } & $\mathbf{R 1}$ & $\mathbf{R 2}$ & $\mathbf{R 3}$ & \\
\hline Local variety & 2 & 3 & 2 & 2.33 \\
\hline Leccino & 5 & 7 & 6 & 6 \\
\hline Pendolino & 1 & 3 & 2 & 2 \\
\hline Coratina & 1 & 2 & 2 & 1.66 \\
\hline Chetoui & 2 & 2 & 4 & 2.66 \\
\hline
\end{tabular}

Table 6a: Analysis of variance for number of roots plant ${ }^{-1}$ through air layering with different Olive varieties.

\begin{tabular}{|c|c|c|c|c|c|}
\hline Source & DF & SS & MS & F & P \\
\hline Repli & 2 & 4.1333 & 2.06667 & & \\
\hline Varieties & 4 & 36.9333 & 9.23333 & 19.10 & 0.0004 \\
\hline Error & 8 & 3.8667 & 0.48333 & & \\
\hline Total & 14 & 44.9333 & & & \\
\hline Grand mean & 2.9333 & $\mathrm{Cv}$ & 23.70 & & \\
\hline
\end{tabular}

LSD value at $5 \%$ of Probability $=1.3090$

The data recorded for number of roots plant ${ }^{-1}$ is given in (Table 6) and analysis of variance is presented in (Table 6a). The analysis of variance showed that data related to number of roots plant ${ }^{-1}$ were significantly different. The mean table showed that maximum number of roots plant ${ }^{-1}$ were recorded for Leccino (6), followed by Chetoui (2.66 days), while minimum number of roots plant ${ }^{-1}$ were in Coratina (1.66). The difference in number of roots plant ${ }^{-1}$ for different varieties is related to the climatic 
condition of Mardan. Its seems that Coratina does not have more favorable climatic condition compared to the Leccino. Leccino is more favorable to the climate of Mardan then that of other varieties that's why Leccino variety showed better results for number of roots plant-1. It is noticed that maximum number roots plant $\mathrm{t}^{-1}$ occurred in Leccino. While minimum number roots plant $^{-1}$ occurred in Coratino variety.

\section{Root weight (gm)}

The data recorded for root weight is given in and analysis of variance is presented. The analysis of variance showed that data related to root weight were significantly different. The mean table showed that maximum root weight was recorded for Local $(0.67 \mathrm{gm})$, followed by Chetoui $(0.40 \mathrm{gm})$, while minimum root weight were in Coratina $(0.17 \mathrm{gm})$. The difference in root weight for different varieties is related to the climatic condition of Mardan. Its seems that Coratina does not have more favorable climatic condition compared to the Local variety. Local variety is more favorable to the climate of Mardan then that of other varieties that's why Local variety showed better results for root weight. It is noticed that maximum root weight occurred in Local variety. While minimum root weight occured in Coratino variety.

\section{Conclusion}

From the present experiment it was concluded that the cultivar Leccino responded very well to air-layering in the agro climatic conditions of Mardan for the parameters, minimum days to callus formation, days to rooting, root diameter ( $\mathrm{mm}$ ), maximum number of rootsplant $\mathrm{t}^{-1}$.

\section{Recommendation}

On the basis of the present findings the following recommendation can be given:

Leccino variety should be used under the agro-climatic conditions of Mardan for air-layering in Olive cultivars.

\section{References}

1. Hadith of Sunan Al-Darimi, Ch. 69, pp.103.

2. Simmonds NW (1976) Evolution of crop plants. Longman Group Ltd. London, UK, pp. 219-221.

3. Munir (2009) Various propagation approaches in olive. B.Sc (Hons) internship report KP. Agric Univ Peshawar, Pakistan, p. 22-23.

4. Medial F, Quezel p, Besnard G, Khadar B (2001) Systematics, ecology and phylogeographic significance of Oleaeuropaea L. ssp. maroccana (Greuter \& Burdet) P P. Vargas et al., a relictual olive tree in south-west Morocco. Botanical Journal of the Linnean Society 137: 249-266.

5. Pietro RD, B. Carlo (2002) A phytosiological analysis of abandoned olive grove grasslands of Ausonimountains. 2(3): 73-93.
6. Alwazir A (2002) Uprooting olive trees in Palestine.

7. Lerner B (2001) New plants from layering. Dept. Of Horticulture, Purdue University, West Lafayette, Indiana, USA.

8. Sileshi G, FK Akinnifesi, A Mkonda, OC Ajayi (2007) Effect of growth media and fertilizer application on biomass allocation and survival of UapacakirkianaMüell Arg. seedlings. Science Res Essay 2(9): 402-415.

9. Ahmad S, N Ahmad, F Wahid, M Sajid, I Hussain, et al. (2014) Propagation of Olive Cultivars through Air Layerage. Journal of Agriculture and Veterinary Science 7(1): 121-125.

10. Awan A A, I Hussain, N Rehman, A Jan, N Ali (2000) Effect of Different Media and Timing Factor on Rooting of Litchi (Litchi chinensis) Plant through Air Layering. Pakistan Journal Of Biological Sciences 3(11): 1809-1810.

11. Chawla W, K Mehta, N Chauhan (2012) Influence of plant growth regulators on rooting of litchi (Litchi chinensisSonn.) air layers. Asian Journal of Horticulture 7(1): 160-164.

12. Dutta P (2000) Effect of growth regulators on air-layering of sweet orange Citrus sinensis (L.) Osbeck. Environment and Ecology 18(4): 899-901.

13. Fazwa F, AG Rasip, N Lokmal (2009) The effect of growing media on rooting ability in air layering propagation of Citrus hystrix. Journal of Tropical Medicinal Plants 10(1): 101-104.

14. Gohil JH (2014) Effect of Different Concentrations of IBA and NAA on Air Layering of Cashewnut cv. Vengurla 4. Trends in Biosciences 7(5): 351-354.

15. Islam M (2012) Effect of time of operation and rooting media on the success and survivility of litchi air-layers.

16. Kakon AJ, MA Rahim, MS Alam (2005) Effect of Different Post Detachment Conditions on the Survivability and Growth Performance of Two Varieties of Guava Air-layers. Asian Journal of Plant Sciences 4(2): 149-153.

17. Kumar S, T Sakthivel, R Chithraichelvan, G Karunakaran (2007) Effect of time, media and root inducing auxins on the rooting of Guava (cv. Allahabad Safeda) air-layers under high rainfall zone. Annals of Agricultural Research 28(1).

18. Maurya RP, DM Lewis, JSA Chandler (2013) Studies on the Propagation of Jamaican Ackee (Blighiasapida L.) by Air-layering. HortScience 48(10): 1298-1300.

19. Paul R, C Aditi (2009) IBA and NAA of 1000 ppm induce more improved rooting characters in air-layers of waterapple (Syzygiumjavanica L.). Bulgarian J Agric Sci 15(2): 123-128.

20. Rehman RU, AH Shah, AA Awan, H Ali (2013) Response of olive cultivars to rooting through air layering in different growth media. Sarhad J Agric 29(1): 1-5.

21. Rehman M, AA Awan, O Khan, I Haq (2013) Response of olive cultivars to air-layering at various timings. Pakistan. J Agri Sci 50(4): 555-558.

22. Rymbai H, GS Reddy (2010) Effect of IBA, time of layering and rooting media on air-layers and plantlets survival under different growing nursery conditions in guava. Indian Journal of Horticulture 67(4): 99104.

23. Singh D, S Pathak (2012) Effect of IBA and NAA on propagation of 
(C) This work is licensed under Creative (1) Commons Attribution 4.0 Licens BY DOI:10.19080/IJESNR.2017.03.555610
Your next submission with Juniper Publishers will reach you the below assets

- Quality Editorial service

- Swift Peer Review

- Reprints availability

- E-prints Service

- Manuscript Podcast for convenient understanding

- Global attainment for your research

- Manuscript accessibility in different formats ( Pdf, E-pub, Full Text, Audio)

- Unceasing customer service

Track the below URL for one-step submission https://juniperpublishers.com/online-submission.php 